University of Wollongong

Research Online

Faculty of Engineering - Papers (Archive)

Faculty of Engineering and Information

Sciences

$1-1-2011$

\title{
Simultaneous activated carbon adsorption within a membrane bioreactor for an enhanced micropollutant removal
}

\author{
Xueqing Li \\ University of Wollongong, xq1895@uow.edu.au \\ Faisal I. Hai \\ University of Wollongong, faisal@uow.edu.au \\ Long Nghiem \\ University of Wollongong, longn@uow.edu.au
}

Follow this and additional works at: https://ro.uow.edu.au/engpapers

Digitalrt of the Engineering Commons

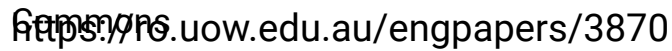

Network

Logo

Recommended Citation

Li, Xueqing; Hai, Faisal I.; and Nghiem, Long: Simultaneous activated carbon adsorption within a membrane bioreactor for an enhanced micropollutant removal 2011, 5319-5324.

https://ro.uow.edu.au/engpapers/3870

Research Online is the open access institutional repository for the University of Wollongong. For further information contact the UOW Library: research-pubs@uow.edu.au 


\section{Simultaneous activated carbon adsorption within a membrane bioreactor for an enhanced micropollutant removal}


10 Abstract: Significant adsorption of sulfamethoxazole and carbamazepine to powdered activated 11 carbon (PAC) was confirmed by a series of adsorption tests. In contrast, adsorption of these 12 micropollutants to the sludge was negligible. The removal of these compounds in membrane 13 bioreactor (MBR) was dependent on their hydrophobicity and loading as well as the PAC 14 dosage. Sulfamethoxazole exhibited better removal rate during operation under no or low (0.1 $15 \mathrm{~g} / \mathrm{L})$ PAC dosage. When the PAC concentration in MBR was raised to $1.0 \mathrm{~g} / \mathrm{L}$, a sustainable and 16 significantly improved performance in the removal of both compounds was observed-the 17 removal efficiencies of sulfamethoxazole and carbamazepine increased to $82 \pm 11$ and $92 \pm 15 \%$ 18 from the levels of $64 \pm 7 \%$, and negligible removal, respectively. The higher removal efficiency of 19 carbamazepine at high $(1.0 \mathrm{~g} / \mathrm{L})$ PAC dosage could be attributed to the fact that carbamazepine is 20 relatively more hydrophobic than sulfmethoxazole, which subsequently resulted in its higher 21 adsorption affinity toward PAC.

22 Keywords: adsorption, biodegradation, membrane bioreactor, micropollutant, powdered 23 activated carbon. 


\section{Introduction}

27 The widespread occurrence of micropollutants in raw sewage, secondary treated effluent and sewage impacted water bodies as well as the associated environmental health concerns present an underlying challenge for the implementation of water recycling. Owing to several advantages including excellent effluent quality, low sludge production, small foot print, and flexibility in future expansion, membrane bioreactor (MBR) has been widely recognized as the next generation of wastewater treatment processes (Judd, 2008). Consequently, considerable dedicated research efforts have been devoted to the assessment of micropollutant removal using MBR (Clara et al., 2005; Kimura et al., 2005; Nghiem et al., 2009; Radjenovic et al., 2009; Visvanathan et al., 2005). Adsorption and subsequent biodegradation of the micropollutants are the dominant removal processes, and are influenced by operational conditions such as hydraulic retention time (HRT), sludge retention time (SRT), biomass concentration, temperature and $\mathrm{pH}$ (Cirja et al., 2008). This results in a rather variable and uncertain removal performance. Previous studies have indicated significant variation in the removal of micropollutants by MBRs, ranging from near complete removal for some compounds (e.g. ibuprofen and bezafibrate) to almost no removal for several others (e.g. carbamazepine and diclofenac) (Clara et al., 2005; Kim et al., 2007; Kimura et al., 2005; Nghiem et al., 2009).

Hydrophobic compounds can be removed from the influent via adsorption to the sludge particles present in the system. Therefore, when the SRT in the wastewater treatment system is sufficiently high (at least 8 d) the removal of organic compounds through adsorption and subsequent biodegradation can be enhanced (Cirja et al., 2008). Compounds containing complex structure and toxic groups (such as halogens and nitro group), however, can show higher resistance to biodegradation and tend to have very low removal (Kimura et al., 2005). Because the adsorption of micropollutants onto sludge facilitates their removal in the biological processes, it is envisaged that addition of adsorbents such as powdered activated carbon (PAC) directly into the MBR can lead to significant retention of soluble micropollutants. Due to the complete retention of sludge by the membrane and application of longer SRT, the retained micropollutants may be efficiently removed in an MBR to which PAC has been added. 
54 The PAC-amended MBR to date has been mainly studied in relation to membrane fouling mitigation (Guo et al., 2008) and rarely to assess recalcitrant pollutant removal enhancement

56 (Hai et al., 2008). Only one study (Zhang et al., 2008) to date have explored PAC-amended

57 MBR specifically for the removal of micropollutants. Although Zhang et al., (2008) confirmed

58 improved removal efficiency, a comprehensive understanding of the involved phenomena is yet

59 to be developed.

This study aimed to investigate the long-term removal performance of two chemically different pharmaceutically active compounds namely sulfamethoxazole and carbamazepine in a PACamended MBR system. In order to explain the performance of the MBR, the adsorption capacities of PAC and MBR sludge were compared in batch tests. The effects of compound structure and its capacity to adsorb onto PAC on their removal efficiencies were discussed. Special focus was given to the effects of micropollutant loading rate, PAC concentration in MBR and the role of membrane filtration on the overall removal of the two selected micropollutants. This study provides unique insights into the strategies to enhance micropollutant removal.

\section{Materials and methods}

\subsection{Model micropollutants and synthetic wastewater}

Two micropollutants, namely sulfamethoxazole (SMX) and carbamazepine (CBZ), were selected in this study on the basis of their widespread occurrence in domestic sewage. These compounds have similar molecular weights; however, their dissociation constants and effective hydrophobicity $(\log$ D) differ markedly (Table 1). SMX is a sulfonamide antibiotic with very low hydrophobicity. CBZ, which is an anti-epileptic drug, is composed of two benzene rings fused to an azepine group, which in turn is connected to an amide group. The selected micropollutants were of analytical grade and were purchased from Sigma-Aldrich (Saint Louis, MO, USA). Stock solution was prepared at a concentration of $1 \mathrm{~g} / \mathrm{L}$ in pure methanol, stored in refrigerator and was used within less than a month.

A previously reported (Zhang et al., 2006) synthetic wastewater was used in this study to simulate high strength municipal wastewater and to accelerate sludge build-up in the reactor. The concentrated synthetic wastewater was prepared and stored in a refrigerator at $4^{\circ} \mathrm{C}$. It was then diluted with distilled water on a daily basis to make up a feed solution containing glucose (800 
$\mathrm{mg} / \mathrm{L})$, peptone (150 mg/L), $\mathrm{KH}_{2} \mathrm{PO}_{4}(35 \mathrm{mg} / \mathrm{L}), \mathrm{MgSO}_{4}(35 \mathrm{mg} / \mathrm{L}), \mathrm{FeSO}_{4}(20 \mathrm{mg} / \mathrm{L})$, and sodium acetate $(450 \mathrm{mg} / \mathrm{L})$. All the chemicals were of analytical grade and were obtained from Chemsupply, SA, Australia. Although the studied micropollutants can be found in municipal wastewater in the range from a few $\mathrm{ng} / \mathrm{L}$ to tens of $\mu \mathrm{g} / \mathrm{L}$, a rather high micropollutant loading was applied in this study in order to confirm the capacity of the proposed PAC amended MBR. Each of the micropollutants was continuously introduced to the feed solution at a concentration of $750 \mu \mathrm{g} / \mathrm{L}$. The feed solution was kept in a stainless steel reservoir at room temperature $\left(22 \pm 2^{\circ} \mathrm{C}\right)$.

\section{2 Design and operating conditions of the MBR}

A laboratory scale MBR set-up consisting of a glass reactor with active volume of $14 \mathrm{~L}$, two air pumps, a pressure sensor, and influent and effluent pumps was used in this study. One Sterapore SADF $^{\mathrm{TM}}$ (SADF0790M mini module) submerged PVDF hollow fiber membrane module supplied by Mitsubishi Rayon Engineering, Japan was used in this set-up. The membrane has a nominal pore size of $0.4 \mu \mathrm{m}$, with a total effective membrane surface area of $0.074 \mathrm{~m}^{2}$. Transmembrane pressure was continuously monitored using a high resolution $( \pm 0.1 \mathrm{kPa})$ pressure sensor (Vacuum meter 840064, Cole-Parmer Instrument Co., Australia) which was connected to a personal computer for data recording. The personal computer was also used to control the permeate peristaltic pump to operate the membrane under a selected average flux of $0.19 \mathrm{~m}^{3} /\left(\mathrm{m}^{2} . \mathrm{d}\right)$ on a 5 minutes on/off cycle. Flow rate of the influent pump was matched with that of the permeate pump to maintain a constant reactor volume. The reactor was seeded with activated sludge from a laboratory scale MBR operated long term for treatment of a broad spectrum of micropollutants (Tadkaew et al., 2010). The hydraulic retention time was set at 24 hours. Performance of the MBR setup with regard to basic water quality parameters was first monitored for about 2 months and then the specific investigations of the current study were initiated under a mixed liquor suspended solids (MLSS) concentration of approximately $11 \mathrm{~g} / \mathrm{L}$. Except for MLSS sampling, no sludge was extracted from the reactor. PAC (PS1000, Activated carbon technologies Pty Ltd, Victoria, Australia) was added into the MBR on day 32 and day 64 of continuous operation to obtain a PAC concentration of 0.1 and $1.0 \mathrm{~g} / \mathrm{L}$, respectively in the MBR. According to the manufacturer, the iodine number and D50 value of the PS1000 were 1160 and $22.3 \mu \mathrm{m}$, respectively. The specific surface area of this PAC was at least $1000 \mathrm{~m}^{2} / \mathrm{g}$. 
113 The set-up was housed in an air-conditioned room to maintain the temperature within a range of $22 \pm 2{ }^{\circ} \mathrm{C}$. The mixed liquor $\mathrm{pH}$ could be maintained at $7.8 \pm 0.1$.

\subsection{Batch adsorption test}

PAC was added in amounts ranging from 10 to $30 \mathrm{mg}$ in glass beakers containing $150 \mathrm{~mL}$ solutions of each micropollutant separately. The test solutions were then incubated for 24 hours under $25^{\circ} \mathrm{C}$ and $150 \mathrm{rpm}$ in a temperature controlled rotary shaker (BL 4500, Bioline, Edward Instrument Company, NSW, Australia). Because of the high adsorption capacity of PAC, a rather high initial concentration of $30 \mathrm{mg} / \mathrm{L}$ of the micropollutants in the test solutions was applied. This confirmed the inclusion of the MBR influent micropollutant concentration (750 $\mu \mathrm{g} / \mathrm{L})$ within the range of equilibrium concentrations obtained during the batch adsorption test. Batch adsorption test with sludge was performed with sludge collected from MBR on day 25. In order to exclude biodegradation, the sludge was first autoclaved (SA-252, Bio-Clean, Medical Industries, Pty, NSW, Australia) at $121^{\circ} \mathrm{C}$ and $1.2 \mathrm{~kg} / \mathrm{cm}^{2}$. The autoclaved mixed liquor was then repeatedly centrifuged (Allegra X-12R, Beckman Coulter, USA) at $3270 \mathrm{G}$ and washed with Milli-Q water to minimize the amount of residual micropollutant. Then 80-480 mg sludge (dry weight) samples were incubated with micropollutant solutions in the same manner as described above.

\subsection{Analytical methods}

A Shimadzu HPLC system (Shimadzu, Kyoto, Japan) equipped with a Supelco Drug Discovery C-18 column (with diameter, length and pore size of $4.6 \mathrm{~mm}, 150 \mathrm{~mm}$, and $5 \mu \mathrm{m}$, respectively) and a UV-Vis detector was used to measure the concentrations of the trace organic contaminants in the feed and permeate. The detection wavelength was set at $280 \mathrm{~nm}$. The mobile phase used

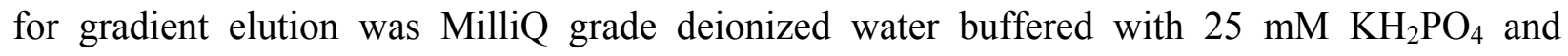
acetonitrile, which was delivered at $1 \mathrm{~mL} / \mathrm{min}$ through the column. A sample injection volume of $50 \mu \mathrm{L}$ was used. Total organic carbon (TOC) and total nitrogen (TN) were analyzed using a Shimadzu TOC/TN-V $\mathrm{V}_{\mathrm{CSH}}$ analyzer (Japan). TOC analysis was conducted in non-purgeable organic carbon (NPOC) mode. Samples were kept at $4^{\circ} \mathrm{C}$ until analyzed and calibrations were performed in the range between 0 and $1000 \mathrm{mg} / \mathrm{L}$ and 0 to $100 \mathrm{mg} / \mathrm{L}$ for TOC and TN, respectively. MLSS concentration in the reactor was measured in accordance to the Standard Methods for the Examination of Water and Wastewater (Clescerl et al., 2005). Removal 
143 efficiency was calculated as $R=100 \times\left(1-\frac{C_{E f f}}{C_{I n f}}\right)$, where $C_{E f f}$ and $C_{\text {Inf }}$ are effluent (or permeate)

144 and influent concentrations $(\mu \mathrm{g} / \mathrm{L})$, respectively. It is noteworthy that the term removal here does 145 not necessarily indicate complete mineralization of the trace organics to carbon dioxide and 146 water. A spectrophotometer (UV 1700, Shimadzu, Japan) was used to measure the diminution of 147 UV absorbance after MBR treatment.

\section{Results and discussion}

\subsection{Micropollutant adsorption capacity of MBR sludge and PAC}

150

The batch adsorption test data for PAC fitted both the Langmuir and Freundlich isotherms very well (Table 2). The partitioning coefficients (K) estimated from the Freundlich isotherm indicated slightly higher adsorption of CBZ onto PAC in comparison to SMX, while the maximum adsorption capacities $\left(\mathrm{q}_{\mathrm{m}}\right)$ estimated from the Langmuir isotherm were almost the same (approximately $280 \mathrm{mg} / \mathrm{gm}$ ) for the two compounds. The reported data is consistent with the reported high adsorption capacity of different micropollutants onto PAC (Kyriakopoulos and Doulia, 2006; Nowotny et al., 2007). The adsorption data is particularly in good agreement with the CBZ adsorption capacity onto PAC reported by Zhang et al. (Zhang et al., 2008). No information about SMX adsorption on PAC could be found in the literature for comparison. Nevertheless, more relevant to our study was the fact that the batch test data confirmed our expectation of enhanced adsorption of the micropollutants onto PAC.

The test data regarding adsorption of SMX and CBZ onto MBR sludge fitted poorly to the adsorption isotherms. Accordingly, instead of the isotherm parameters, the maximum unit adsorption values (approximately 0.017 and $0.020 \mathrm{mg} / \mathrm{g}$ for SMX and CBZ, respectively) observed during the experiment are reported for comparison purposes (Table 2). The observed negligible adsorption of SMX and CBZ onto sludge is in line with the literature reports (Abegglen et al., 2009; Tadkaew et al., 2010).

\subsection{Basic performance of the MBR}

In order to confirm that the micropollutants removal efficiencies used in analyses were obtained under stable biological activity in the MBR the basic water quality parameters and the key operational parameters were periodically monitored. The average values of the different basic Li, X., Hai, F. Ibney. and Nghiem, L. D. (2011). Simultaneous activated carbon adsorption within a membrane bioreactor for an enhanced micropollutant removal. Bioresource Technology, 102 (9), 5319-5324. 
171 parameters during the MBR operation are shown in Table 3. For the most part of the operation 172 the TOC removal remained around 97\%. However, two periods, when the TOC removal 173 deviated from the original level, can be noticed in Figure 1a. Relatively lower TOC removal 174 during day 21-30 and 46-53 can be attributed to the malfunctioning of the air conditioning 175 system around at the same time which caused the temperature of the reactor during that period to 176 frequently fall below $15^{\circ} \mathrm{C}$. Previous studies have demonstrated the effect of low temperature on 177 TOC and especially on TN removal in MBR (Chiemchaisri and Yamamoto, 1994; Chu et al., 178 2005). Although a significant drop in TOC removal may not be encountered up to a temperature 179 of $10^{\circ} \mathrm{C}$, the level of TOC variation observed in our experiment can be explained by the low 180 temperature effect.

181 The TN removal rate, on the other hand, remained stable over the whole period with an average 182 value of $96 \pm 5 \%$. In the absence of an anoxic compartment, the denitrification capacity of the 183 MBR system used in this study was limited. However, the synthetic wastewater in use had a 184 significantly high carbon to nitrogen ratio $(\sim 20)$, therefore, the high TN removal observed here 185 186 could possibly be attributed to the conversion of dissolved organic nitrogen to biomass, which would then be retained by the membrane. This appears to be also the reason why TN removal was less influenced by the accidental temperature drop in the reactor.

Only slightly improved removal rates of both TOC and TN were observed following the higher 189 190 dose PAC addition on day 64 (Figure 1a). The micropollutants contributed a negligible portion of the TOC and TN (few $\mu \mathrm{g} / \mathrm{L}$ in contrast to combined TOC and TN of 500 and $25 \mathrm{mg} / \mathrm{L}$, respectively) and, hence, the variations of SMX and CBZ removal were not reflected in the TOC 192 and $\mathrm{TN}$ profiles.

193 It is noteworthy that the continuous high dosing of micropollutants to the feed water for extended 194 period did not result in any abnormal variation in TOC/TN removal, MLSS concentration, 195 turbidity (Table 3) or hydraulic performance of the membrane (data not shown). The UV 196 absorbance of permeate in fact decreased many folds after PAC addition in the MBR. Delgado et al. (2010) suggested that the inhibitory effect of pharmaceutical compounds can be off-set by a 198 high biomass over substrate ratio typical of MBR, and hence no discernible effect on basic water 199 quality parameters would be observed.

Li, X., Hai, F. Ibney. and Nghiem, L. D. (2011). Simultaneous activated carbon adsorption within a membrane bioreactor for an enhanced micropollutant removal. Bioresource Technology, 102 (9), 5319-5324. 


\subsection{Micropollutant removal before PAC addition}

201 The removal rate of CBZ remained very low for the entire period of operation without PAC 202 (Figure 1). No significant removal of CBZ was observed during the first week of the experiment. 203 The poor biodegradation rate of CBZ during MBR treatment has also been widely reported in the 204 literature. To date both laboratory and pilot scale MBR plant studies have reported negligible (Abegglen et al., 2009; Kim et al., 2007; Radjenovic et al., 2009) to moderate (Bernhard et al., 2006; Kreuzinger et al., 2004; Tadkaew et al., 2010) removal of CBZ, usually less than 10\%. The highest removal (around 30\%) in conventional MBR to date has been reported by Urase et al. (2005) under acidic $\mathrm{pH}$. The very low removal rate of CBZ observed in this study without PAC addition is, hence, not surprising. The removal rate occasionally rose up to $10 \%$ in the following days, presumably due to the progressive conditioning of the sludge. However, towards the end of the first period of accidental low temperature in the MBR (day 21-30), as mentioned

212 before, the removal rate plummeted to almost zero again. Although it is difficult to pinpoint an appropriate temperature range, it is generally accepted in the literature that lower temperature operation (especially under $15^{\circ} \mathrm{C}$ ) can cause deteriorated micropollutant removal rate. For instance, Carballa et al. (2005) previously reported better removal of certain pharmaceuticals under $25^{\circ} \mathrm{C}$ than in $12^{\circ} \mathrm{C}$. It is interesting, however, to note that in this study the deterioration of micropollutant removal started one week or so later than the onset of the TOC removal deterioration.

219

220

221

222

223

224

225

226

227

In case of SMX, the MBR exhibited removal rates within the range of $64 \pm 7 \%$ for the first 28 days of operation without PAC (Figure 1). After that the removal rate dropped to approximately half of the initial rate due to the adverse effect of accidental low temperature in the MBR. SMX removal rates in the range between 50 - $92 \%$ have been reported in the literature (Clara et al., 2005; Radjenovic et al., 2009; Tadkaew et al., 2010). Results reported here indicate that SMX is more readily biodegradable than CBZ. Accordingly it is particularly important to implement a strategy to enhance the removal efficiency of CBZ during wastewater treatment.

\subsection{Effect of PAC addition on micropollutant removal}

\subsubsection{Removal under low PAC dosage}

Li, X., Hai, F. Ibney. and Nghiem, L. D. (2011). Simultaneous activated carbon adsorption within a membrane bioreactor for an 
The first dose of PAC $(0.1 \mathrm{~g} / \mathrm{L})$ was added into the MBR on day 32 immediately after the return of the reactor temperature to the expected value $\left(22 \pm 2^{\circ} \mathrm{C}\right)$ following the first incidence of air conditioning system malfunctioning. As noted from the TOC removal profile (Figure 1a) the biological activity had not yet been reinstated to the original level when the PAC was added. Nevertheless the CBZ removal rate instantaneously leaped up from the no removal stage to $87 \%$ following the addition of PAC. A 25\% jump in the removal of SMX also occurred. Higher instantaneous jump in the CBZ removal rate suggests greater adsorption of CBZ onto PAC. PAC can adsorb a wide spectrum of organics and inorganics (Hai et al., 2007; Kyriakopoulos and Doulia, 2006). Although in our study the single solute adsorption isotherms derived using MilliQ water estimated somewhat similar adsorption of the two studied micropollutants onto PAC, under the complex wastewater matrix preferential adsorption of CBZ can be explained by its relatively higher hydrophobicity or $\log \mathrm{D}$ value (Table 1$)$.

The removal rates, however, gradually returned to the lower values that were maintained immediately before the PAC addition. This indicated that the applied PAC dosage was not adequate to provide long enough a retention of the micropollutants for the microbes to complete their biodegradation. The theoretical adsorption capacity of the $0.1 \mathrm{~g} / \mathrm{L} \mathrm{PAC}$ based on the adsorption isotherm (section 3.1) exceeds the micropollutant loading. However, Zhang et al. (2008) estimated that under the competition with other organics in the synthetic wastewater only $30 \%$ of the added PAC into MBR was effectively utilized for CBZ adsorption. It was therefore deemed imperative that a higher PAC dosage would be required to sustain the high micropollutant loading as used in this study. Notably the SMX removal, but not the CBZ removal, started to improve again on day 41, presumably due to the recovery of the biological activity. The delay in CBZ removal rate recovery can be explained by the widely reported (Clara et al., 2005; Kim et al., 2007; Radjenovic et al., 2009) relatively recalcitrant nature of CBZ.

As expected, compared to the level maintained up to day 31 (before addition of PAC) the CBZ and SMX concentrations in permeate decreased significantly following lowering their respective concentrations in the feed to $100 \mu \mathrm{g} / \mathrm{L}$ on day 48. For the next two weeks or so the SMX concentration in permeate remained in the range of $18 \pm 10 \mu \mathrm{g} / \mathrm{L}$. However, the permeate CBZ concentration very often exceeded the $100 \mu \mathrm{g} / \mathrm{L}$ mark during this period and, hence, negative removal rates of $\mathrm{CBZ}$ were calculated based on the feed concentration. This may be explained by 
the fact that the second incidence of accidental temperature drop in the MBR unfortunately coincided with this event of lowering the feed micropollutant concentrations; and CBZ, due to the relative recalcitrance, was more affected by the reduced biological performance. Although the unplanned incidence of temperature drop in MBR restricts accurate quantification of the effect of lower feed concentration on removal rates, it does, on the other hand, manifest the higher sensitivity of $\mathrm{CBZ}$ to change of key operating conditions under no or low dose of PAC.

\subsubsection{Removal under higher PAC dosage}

The beneficial effect of PAC addition, especially in case of CBZ, could be assessed fully after raising the PAC concentration in the MBR to $1.0 \mathrm{~g} / \mathrm{L}$ on day 64 . After increasing the PAC dosage, the $\mathrm{CBZ}$ concentrations in permeate dropped to below $20 \mu \mathrm{g} / \mathrm{L}$ in the following 10 days. Slightly lower permeate concentrations of SMX were also observed during this time.

The permeate quality deteriorated to some extent when the feed micropollutant concentrations were returned to $750 \mu \mathrm{g} / \mathrm{L}$ on day 72 . For the rest of the observation period ( 3 weeks) the SMX concentration in permeate was in the range of $127 \pm 80 \mu \mathrm{g} / \mathrm{L}(83 \pm 11 \%$ removal), which, when compared to the level before PAC addition $(280 \pm 55 \mu \mathrm{g} / \mathrm{L}, 64 \pm 7 \%$ removal), suggests moderate improvement in removal performance. The CBZ concentration in permeate, on the other hand, remained within the $80 \pm 55 \mu \mathrm{g} / \mathrm{L}(92 \pm 15 \%$ removal) range for the same period. This suggests a significant improvement of the permeate quality in terms of CBZ concentration when compared to the concentration observed before PAC addition $(660 \pm 87 \mu \mathrm{g} / \mathrm{L})$. Taking into account the micropollutant loading rate of $0.75 \mathrm{mg} /(\mathrm{L} . \mathrm{d})$ the level of removal achieved in our study by far exceeds that reported before.

\subsection{Additional removal by the MF membrane}

Microfiltration membranes as used in this study cannot retain the two selected micropollutants because of their very large pore size in comparison to the dimensions of these compounds. However, in the filtration of mixed liquor of activated sludge, additional removal by membranes may be expected due to the additional barrier provided by the particle deposition on the membrane surface (Urase et al., 2005). This additional effect is uncertain for hydrophilic compounds in conventional MBR (Reemtsma et al., 2002). Hai et al. (2008) reported significant additional removal of a polar dye by membrane in a PAC-amended MBR. Figure 2 shows the 
average concentrations of $\mathrm{CBZ}$ and $\mathrm{SMX}$ in the reactor supernatant and also the ratios of permeate to supernatant concentrations for the two compounds during operation with and without PAC. It is evident that after the PAC addition the membrane achieved significant additional removal of both the micropollutants, especially of CBZ. Nevertheless it should be noted that although sorption on to membrane cake layer may have increased the retention time of the micropollutants to some extent, without subsequent biodegradation long term and stable removal as seen in our study would not be possible.

\subsection{Effects of feed micropollutant concentration and PAC dosage}

Table 4 shows the CBZ and SMX concentrations in permeate under different combinations of feed micropollutant concentration and PAC dose. In order to have stable removal the biodegradation rate needs to at least match the influent micropollutant loading which is in excess of the adsorption capacity of the PAC. The overall removal then would depend, among others, on the biodegradation rate and the amount of PAC dosing. For a certain feed concentration (750 $\mu \mathrm{g} / \mathrm{L})$ marked improvement in CBZ removal under a higher PAC dosage $(1.0 \mathrm{~g} / \mathrm{L})$ is in line with the observation reported by Zhang et al. (2008).

It is interesting to note from Table 4 that the concentration of SMX in the permeate was relatively lower than that of $\mathrm{CBZ}$ during all the runs except the last one with higher dosage of PAC $(1.0 \mathrm{~g} / \mathrm{L})$ and higher feed concentration $(750 \mu \mathrm{g} / \mathrm{L})$. The much better removal of SMX over CBZ before PAC addition is, as explained earlier, due to the higher biodegradability of SMX. Under lower PAC dosage the SMX removal was better as due to insufficient adsorption sites the biodegradation rate still predominantly governed the total removal. However, the mode of degradation changes when sufficient PAC is present. In that case, co-adsorption of degrading enzyme and pollutant onto PAC, and subsequent degradation of pollutant occurs on PAC surface (Hai et al., 2008). Our results suggest that in such a case, compounds adsorbing more onto PAC are more likely to have better removal. Under the higher PAC dosage when the influent micropollutant concentrations were $100 \mu \mathrm{g} / \mathrm{L}$ each, SMX was still better removed, presumably as there were still enough adsorption sites for SMX to occupy. However, as the concentration of both SMX and CBZ in feed was raised to $750 \mu \mathrm{g} / \mathrm{L}, \mathrm{CBZ}$ occupied more adsorption sites (competitive adsorption) and was better removed, even though it possesses a more recalcitrant 
structure. The competitive adsorption of CBZ over SMX is also manifested by the lower and more stable concentration of CBZ in the supernatant (Figure 2).

\section{Conclusion}

Improved removal of sulfamethoxazole and carbamazepine by a PAC-amended MBR system was demonstrated. The removal of these compounds was dependent on their hydrophobicity and loading as well as the PAC dosage. $64 \pm 7 \%$ removal of sulfamethoxazole, which has been reported as more biodegradable of the two micropollutants, was registered in contrast to negligible removal of carbamazepine under no or low $(0.1 \mathrm{~g} / \mathrm{L})$ PAC concentration. A sustainable and significantly improved performance in the removal of both compounds was observed, when a high dosage of $1.0 \mathrm{~g} / \mathrm{L}$ of PAC was utilised. The removal efficiencies of sulfamethoxazole and carbamazepine increased to $82 \pm 11$ and $92 \pm 15 \%$, respectively.

\section{Acknowledgments}

The authors wish to thank Professor Kazuo Yamamoto of Environmental Science Centre, University of Tokyo, Japan for arranging the membrane module from MRE, Japan. Activated Carbon Technologies Pty Ltd (Victoria, Australia) is thanked for the provision of PAC sample. The technical assistance of University of Wollongong colleagues Mr Robert Rowlan and Mr. Frank Cabtree is duly acknowledged. Thanks are also due to Ms Sara Gilbertson and Ms Shaza Raini for their assistance in some of the laboratory analyses.

\section{References}

Abegglen, C., Joss, A., McArdell, C.S., Fink, G., Schlüsener, M.P., Ternes, T.A., Siegrist, H., 2009. The fate of selected micropollutants in a single-house MBR. Water Research, 43, 2036-2046.

Bernhard, M., Müller, J., Knepper, T.P., 2006. Biodegradation of persistent polar pollutants in wastewater: Comparison of an optimised lab-scale membrane bioreactor and activated sludge treatment. Water Research, 40, 3419-3428.

Carballa, M., Omil, F., Lema, J.M., 2005. Removal of cosmetic ingredients and pharmaceuticals in sewage primary treatment. Water Research, 39, 4790-4796. 
Chiemchaisri, C., Yamamoto, K., 1994. Performance of membrane separation bioreactor at various temperatures for domestic wastewater treatment. Journal of Membrane Science, 87, $119-129$.

Chu, L.-B., Yang, F.-L., Zhang, X.-W., 2005. Anaerobic treatment of domestic wastewater in a membrane-coupled expended granular sludge bed (EGSB) reactor under moderate to low temperature. Process Biochemistry, 40, 1063-1070.

Cirja, M., Ivashechkin, P., Schäffer, A., Corvini, P., 2008. Factors affecting the removal of organic micropollutants from wastewater in conventional treatment plants (CTP) and membrane bioreactors (MBR). Reviews in Environmental Science and Biotechnology, 7, 6178.

Clara, M., Strenn, B., Gans, O., Martinez, E., Kreuzinger, N., Kroiss, H., 2005. Removal of selected pharmaceuticals, fragrances and endocrine disrupting compounds in a membrane bioreactor and conventional wastewater treatment plants. Water Research, 39, 4797-4807.

Clescerl, L.S., Greenberg, A.E., Eaton, A.D., 2005. Standard Methods for Examination of Water \& Wastewater $21^{\text {st }}$ ed. American Public Health Association

Delgado, L.F., Schetrite, S., Gonzalez, C., Albasi, C., 2010. Effect of cytostatic drugs on microbial behaviour in membrane bioreactor system. Bioresource Technology, 101, 527536.

Guo, W., Vigneswaran, S., Ngo, H.-H., Xing, W., Goteti, P., 2008. Comparison of the performance of submerged membrane bioreactor (SMBR) and submerged membrane adsorption bioreactor (SMABR). Bioresource Technology, 99, 1012.

Hai, F.I., Yamamoto, K., Fukushi, K., 2007. Hybrid Treatment Systems for Dye Wastewater. Critical Reviews in Environmental Science and Technology, 37, 315-377.

Hai, F.I., Yamamoto, K., Nakajima, F., Fukushi, K., 2008. Removal of structurally different dyes in submerged membrane fungi reactor--Biosorption/PAC-adsorption, membrane retention and biodegradation. Journal of Membrane Science, 325, 395-403. 
Judd, S., 2008. The status of membrane bioreactor technology. Trends in Biotechnology, 26, 109116.

Kim, S.D., Cho, J., Kim, I.S., Vanderford, B.J., Snyder, S.A., 2007. Occurrence and removal of pharmaceuticals and endocrine disruptors in South Korean surface, drinking, and waste waters. Water Research, 41, 1013-1021.

Kimura, K., Hara, H., Watanabe, Y., 2005. Removal of pharmaceutical compounds by submerged membrane bioreactors (MBRs). Desalination, 178, 135.

Kreuzinger, N., Clara, M., Strenn, B., Kroiss, H., 2004. Relevance of the sludge retention time (SRT) as design criteria for wastewater treatment plants for the removal of endocrine disruptors and pharmaceuticals from wastewater. Water Science and Technology, 50, 149156.

Kyriakopoulos, G., Doulia, D., 2006. Adsorption of Pesticides on Carbonaceous and Polymeric Materials from Aqueous Solutions: A Review. Separation \& Purification Reviews, 35, 97 191.

Nghiem, L.D., Tadkaew, N., Sivakumar, M., 2009. Removal of trace organic contaminants by submerged membrane bioreactors. Desalination, 236, 127.

Nowotny, N., Epp, B., von Sonntag, C., Fahlenkamp, H., 2007. Quantification and Modeling of the Elimination Behavior of Ecologically Problematic Wastewater Micropollutants by Adsorption on Powdered and Granulated Activated Carbon. Environmental Science \& Technology, 41, 2050-2055.

Radjenovic, J., Petrovic, M., Barceló, D., 2009. Fate and distribution of pharmaceuticals in wastewater and sewage sludge of the conventional activated sludge (CAS) and advanced membrane bioreactor (MBR) treatment. Water Research, 43, 831-841.

Reemtsma, T., Zywicki, B., Stueber, M., Kloepfer, A., Jekel, M., 2002. Removal of SulfurOrganic Polar Micropollutants in a Membrane Bioreactor Treating Industrial Wastewater. Environmental Science \& Technology, 36, 1102-1106. 
395 Tadkaew, N., Sivakumar, M., Khan, S.J., McDonald, J.A., Nghiem, L.D., 2010. Effect of mixed liquor $\mathrm{pH}$ on the removal of trace organic contaminants in a membrane bioreactor. Bioresource Technology, 101, 1494-1500.

Urase, T., Kagawa, C., Kikuta, T., 2005. Factors affecting removal of pharmaceutical substances and estrogens in membrane separation bioreactors. Desalination, 178, 107-113.

400 Visvanathan, C., Thu, L.N., Jegatheesan, V., Anotai, J., 2005. Biodegradation of 401 pentachlorophenol in a membrane bioreactor. Desalination, 183, 455-464.

402 Zhang, J., Chua, H.C., Zhou, J., Fane, A.G., 2006. Factors affecting the membrane performance 403 in submerged membrane bioreactors. Journal of Membrane Science, 284, 54-66.

404 Zhang, L.Q., Urase, T., Feng, L., 2008. Removal of carbamazepine in an enhanced membrane 405 406 407 bioreactor with small dose addition of powdered activated carbon. in: X. Wang, R. Chen (Eds.), Advances in Chemical Technologies for Water and Wastewater Treatment, pp. 199205. 
399 Table 1: Chemical properties of the selected micropollutants.

\begin{tabular}{|l|c|c|}
\hline Micropollutant & $\begin{array}{c}\text { Sulfamethoxazole } \\
\text { (SMX) }\end{array}$ \\
\hline Structure & 253.3 & 236.3 \\
\hline Molecular weight $(\mathrm{g} / \mathrm{mol})$ & 0.9 & 2.67 \\
\hline Log $D($ at $\mathrm{pH} 8)$ & 16 & 0.22 \\
\hline Solubility $(\mathrm{g} / \mathrm{L})$ at $25^{\circ} \mathrm{C}$ and $\mathrm{pH} 8$ & $1.39 \& 5.81$ & $-0.49 \& 13.94$ \\
\hline Dissociation constant $\left(\mathrm{pK} K_{a}\right)$ & & (CBZ) \\
\hline
\end{tabular}


401 Table 2: PAC adsorption isotherm (at $25^{\circ} \mathrm{C}$ ) constants for sulfamethoxazole (SMX) and carbamazepine 402 (CBZ).

\begin{tabular}{llll|lll}
\hline \multicolumn{3}{c|}{ Freundlich isotherm constants } & \multicolumn{3}{l}{ Langmuir isotherm constants } \\
\hline & $\mathrm{K}$ & $1 / \mathrm{n}$ & $\mathrm{R}^{2}$ & $\mathrm{q} \mathrm{m}[\mathrm{mg} / \mathrm{g}]$ & $\mathrm{K}_{1}$ & $\mathrm{R}^{2}$ \\
& {$\left[(\mathrm{mg} / \mathrm{g}) /(\mathrm{mg} / \mathrm{L})^{1 / \mathrm{n}}\right]$} & & & & & \\
\hline $\mathrm{SMX}$ & 166 & 0.26 & 0.94 & 282 & 1.44 & 0.97 \\
$\mathrm{CBZ}$ & 225 & 0.17 & 0.87 & 287 & 7.70 & 0.94 \\
\hline
\end{tabular}

Freundlich isotherm: $\mathrm{q}_{\mathrm{e}}=\mathrm{KC}_{\mathrm{e}}{ }^{1 / \mathrm{n}}$; Langmuir isotherm: $1 / \mathrm{q}_{\mathrm{e}}=\left(1 / \mathrm{q}_{\mathrm{m}} \mathrm{K}_{1}\right)\left(1 / \mathrm{C}_{\mathrm{e}}\right)+1 / \mathrm{q}_{\mathrm{m}}$;

$\mathrm{q}_{\mathrm{e}}=$ equilibrium mass of compound sorbed on unit mass of adsorbent, $\mathrm{C}_{\mathrm{e}}=$ equilibrium concentration of compound in liquid, $\mathrm{q}_{\mathrm{m}}=$ maximum adsorption capacity, $\mathrm{K}=$ partitioning coefficient. Note: Batch test data with MBR sludge fitted neither of the isotherms; however considering single data points, a maximum adsorption of 0.017 and $0.020 \mathrm{mg} / \mathrm{g}$ were estimated for SMX and CBZ, respectively. 
404 Table 3: Basic biological performance of the MBR system.

\begin{tabular}{|c|c|c|c|c|c|}
\hline \multirow{2}{*}{$\begin{array}{c}\text { TOC } \\
\operatorname{removal}(\%)\end{array}$} & \multirow{2}{*}{$\begin{array}{c}\mathrm{TN} \text { removal } \\
(\%)\end{array}$} & \multirow{2}{*}{$\begin{array}{c}\text { MLSS } \\
(\mathrm{g} / \mathrm{L})\end{array}$} & \multirow{2}{*}{$\begin{array}{c}\text { Permeate } \\
\text { turbidity (NTU) }\end{array}$} & \multicolumn{2}{|c|}{$\mathrm{UV}_{254}$ absorbance of the permeate $\left(\mathrm{cm}^{-1}\right)$} \\
\hline & & & & Before PAC addition & After PAC addition \\
\hline $92 \pm 5$ & $96 \pm 5$ & $12 \pm 1$ & $<0.2$ & 0.125 & 0.005 \\
\hline
\end{tabular}

405 
406 Table 4: Concentrations of sulfamethoxazole (SMX) and carbamazepine (CBZ) in permeate under 407 different operating conditions.

\begin{tabular}{ccccc}
\hline \multirow{2}{*}{$\begin{array}{c}\text { Day of } \\
\text { operation }\end{array}$} & $\begin{array}{c}\text { PAC conc. in } \\
\text { MBR, } g / \mathrm{L}\end{array}$ & $\begin{array}{c}\text { Micropollutant } \\
\text { conc. in feed, } \mu \mathrm{g} / \mathrm{L}\end{array}$ & \multicolumn{2}{c}{ Concentration in permeate, $\mu \mathrm{g} / \mathrm{L}^{\mathrm{a}}$} \\
\cline { 4 - 5 } & 0 & 750 & $280 \pm 55$ & $\mathrm{CBZ}$ \\
\hline $3-32$ & 0.1 & 750 & $447 \pm 96$ & $490 \pm \pm 226$ \\
$43-48^{\mathrm{b}}$ & 0.1 & 100 & $18 \pm 10$ & $190 \pm 80$ \\
$49-64^{\mathrm{c}}$ & 1.0 & 100 & $10 \pm 10$ & $22 \pm 10$ \\
$65-72$ & 1.0 & 750 & $127 \pm 80$ & $80 \pm 55$ \\
$73-92$ & & & & \\
\hline
\end{tabular}

${ }^{\mathrm{a}}$ Values indicate mean concentration \pm standard deviation.

${ }^{\mathrm{b}}$ Accidental low temperature in MBR from day 21-30 caused variable removal of both SMX and CBZ.

${ }^{\mathrm{c}}$ Removal of CBZ was more sensitive to accidental low temperature in MBR during day 4653 even though the influent concentration was reduced; SMX showed stable removal due to its relative biodegradability. 


\section{$410 \quad$ LIST OF FIGURE CAPTIONS}

411 Figure 1: TOC and micropollutants removal throughout the operation period: (a) TOC, (b) 412 sulfamethoxazole (SMX), and (c) carbamazepine (CBZ). P1 and P2 indicate points of PAC addition to 413 achieve final concentrations of $0.1 \mathrm{~g} / \mathrm{L}$ and $1.0 \mathrm{~g} / \mathrm{L}$, respectively; $\mathrm{T}$ indicates periods of accidental low 414 temperature in MBR; horizontal bar in each graph indicates respective feed concentration.

415 Figure 2: Relative concentrations of sulfamethoxazole (SMX) and carbamazepine (CBZ) in supernatant 416 and permeate before and after PAC addition in MBR. (Error bars represent the standard deviation of 417 available data points $(n \geq 5)$. Only data corresponding to the highest feed micropollutant concentration 418 of $750 \mu \mathrm{g} / \mathrm{L}$ have been included. 
420 LIST OF FIGURES

421 

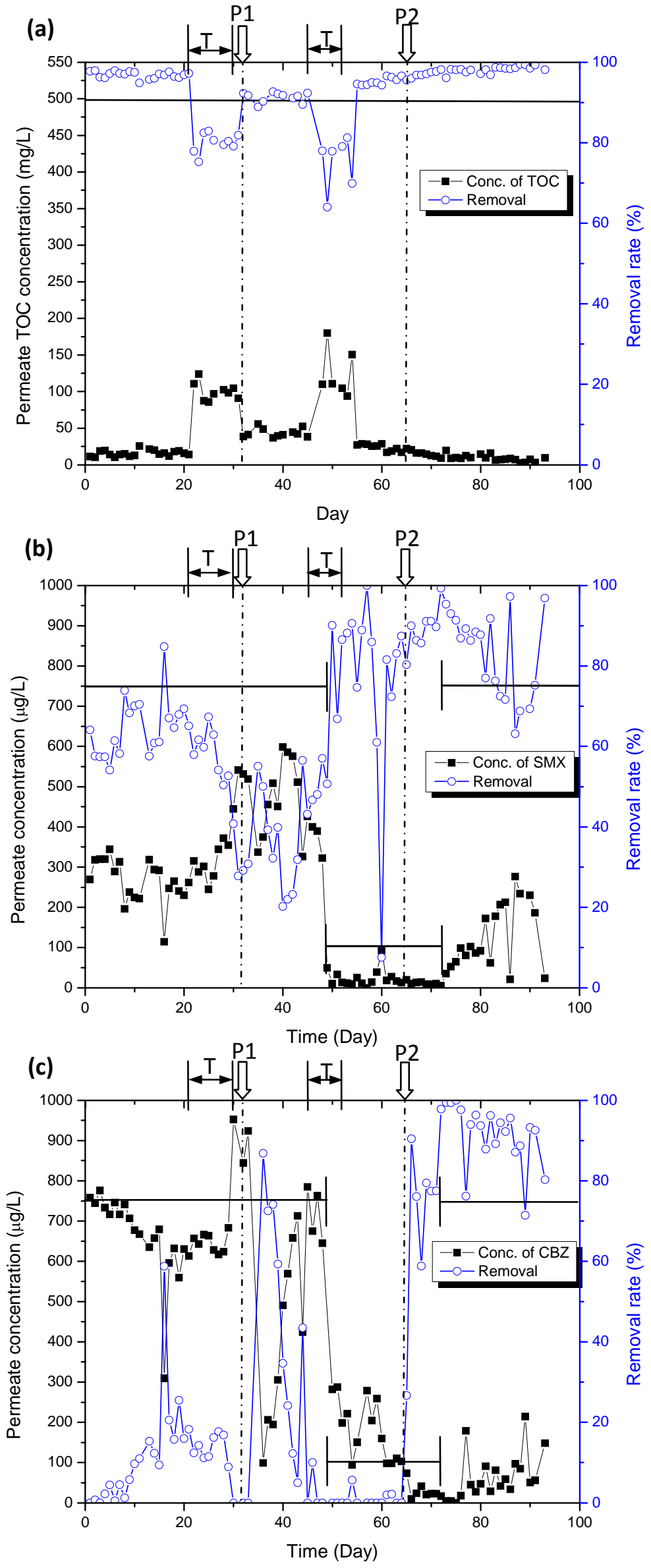


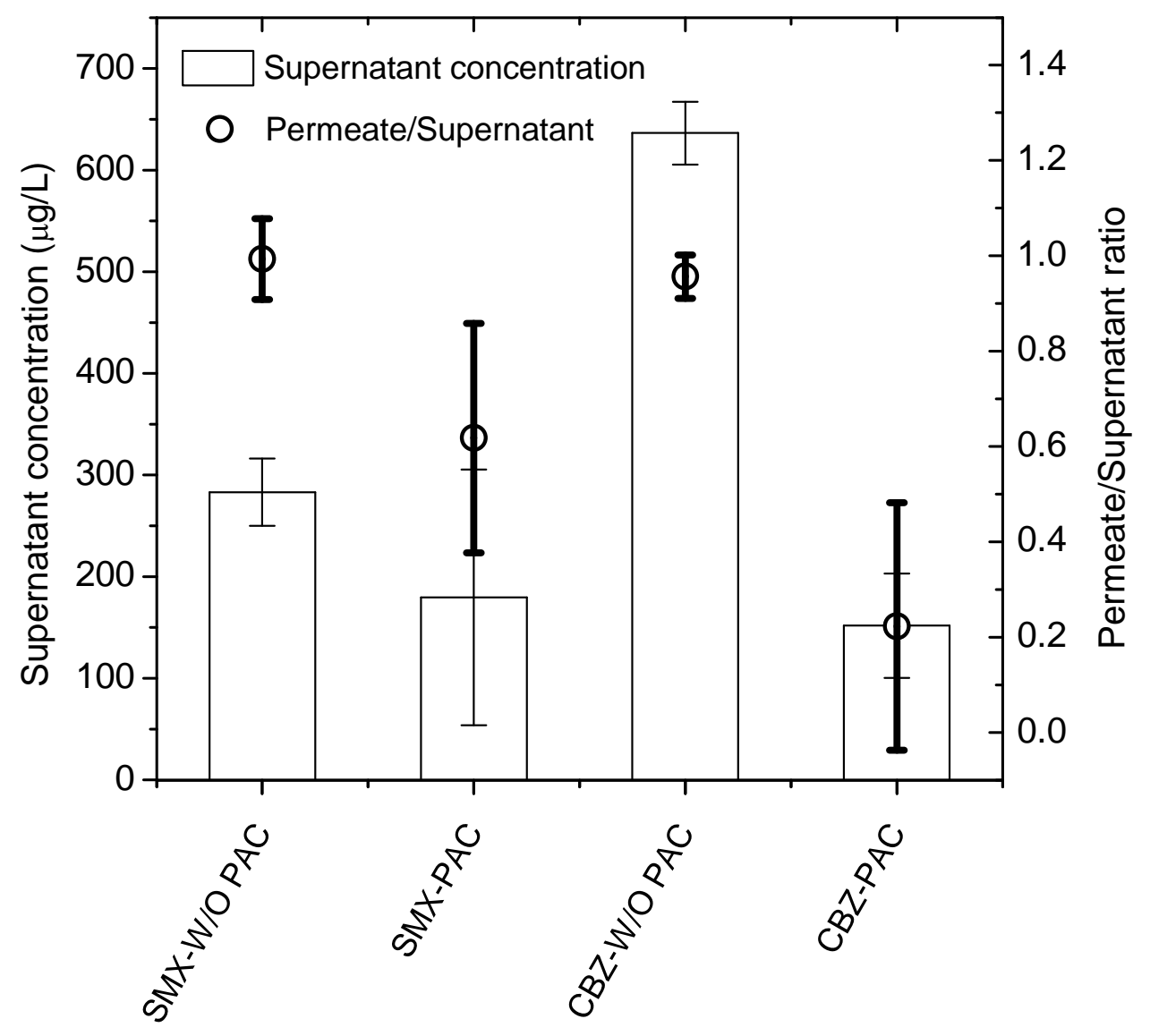

423

$424 \quad$ Figure 2 